\title{
Antinuclear Antibodies in Autoimmune Diseases
}

\author{
Nagwa Mohammed Abo Elmahasen, Zienab Mohammed Mahmoud \\ Deyab, Hesham Moslem Hefney \\ Clinical and Chemical Pathology Faculty of medicine Sohag University
}

\begin{abstract}
Autoimmune disorders represent various clusters of sicknesses portrayed by cell and humoral reactions against self. The humoral immune system reactions are coordinated against differed segments inside the cell and outside the cell. Immune system infections, for example, fundamental lupus erythematosus (SLE), rheumatic inflammatory disease, foundational sclerosis, and antineutrophil cellular material protein-related general vasculitis, are more often than not over the span of the frequency of non-organ-explicit autoantibodies. Antinuclear antibodies (ANA) may be a term for an outsized and heterogeneous cluster of current antibody. reflective the important uses, ANA is utilized for diagnosing or criteria for lupus, foundational Sclerosis, blended connective tissue infection and undifferentiated connective tissue ailment. ANA has been determined by indirect immunofluorescence measure (IIFA) for quite a long time. Elective procedures were created testing the exemplary IIFA as the interest for ANA testing expanded. These stages vary in their antigen profiles, affectability, and particularity, raising vulnerabilities with respect to institutionalization and elucidation of incongruent outcomes.
\end{abstract}

Keywords: ANA, Classification, detection

\section{Introduction}

Autoimmune diseases represent various clusters of sicknesses portrayed by cell and humoral reactions against self. The humoral immune system reactions are coordinated against differed segments inside the cell and outside the cell. Immune system infections, for example, fundamental lupus erythematosus, rheumatic inflammatory disease, foundational sclerosis, and antineutrophil cellular material proteinrelated general vasculitis, are more often than not over the span of the frequency of non-organ-explicit autoantibodies (1). ANA may be a term for an outsized and heterogeneous cluster of current antibody. reflective the important uses, ANA is utilized for diagnosing or criteria for lupus, foundational Sclerosis, blended connective tissue infection and undifferentiated connective tissue ailment (2). In the twelfth Workshop on Autoantibodies made in Brazil, in
2014 a session was done to building accord on the shading design in the ANA circuitous immunofluorescence test on HEp-2 cells. The examples are condensed in three fundamental gatherings (atomic examples, cytoplasm, and mitosis) and each example has been clarified in subtleties (3). Another gathering for the Consensus of the Pattern of ANA was done in 2015, Germany. The Consensus plan was made to talk about ANA examples with respect to cell parts: core, nucleolus, cytoplasm, and mitotic gear. The classification consists of 11 patterns. Six nuclear patterns of competent levels that can be reported are homogeneous, grainy, finely speckled, centromere, separate nuclear points, and nucleolar. The five reported cytoplasmic patterns reported include fibrillar, mottled, such as reticular / mitochondria, polar / Golgi, stem and 
ring (4). Factors that lead to ANA production are mostly unknown, with some reports which show a higher incidence of ANA in women and old persons. percentage of the ANApositive population may represent the stage preceding appearance of autoimmune disease, based on the notice that autoantibodies are mostly produced before appearance of the clinical manifestations of the disease (5).

Classification of antinuclear
antibodies:
According to the coloring pattern
observed in the ANA
immunofluorescence test not directly
on cell HE-2:

A. Nuclear pattern: homogeneous, spotted, fringe/edge, nucleolar, centromeric, multiplying cell atomic antigen, atomic specks, atomic film, diffuse granules.

B. Cytoplasmic pattern: speckled, as mitochondria, such as ribosomes, Golgi apparatus, such as lysosomes, cytoskeletal filaments.

C. Mitotic pattern: mitotic axle, centrosom, NuMA (atomic mitotic hardware), midbody, CENP-F (protein centromere) (4).

\section{ANA titer:}

The level for FANA energy has been 1:40 with more noteworthy clinical hugeness by and large has been thought to relate with higher titers (7).

\section{Causes of positive ANA:}

\section{-SLE}

-Discoid lupus

-Polymyositis

-Musculoskeletal manifestations with positive ANA

-fundamental sclerosis.

-Dermatomyositis

- Rheumatoid joint pain

- Blended connective tissue infection $(8,9)$.
- A few sorts of hepatitis: immune system hepatitis, viral liver illnesses (10).

-viral contaminations (11).

-positivity due to prescriptions (12).

- some individuals who never show malady (13).

- some by and by ordinary, solid individuals who show ailment after years (13).

\section{Methods of detection of antinuclear antibodies:}

Many tests are used for the determination of ANA such as indirect antinuclear antibody immunofluorescence tests and the ELISA test which is the most used test. with other tests that incorporate immunodiffusion, counterimmunoelectrophoresis techniques, immunoblot, two delicate and explicit tests utilized for research settings; and chemical restraint tests (eg, hindrance of topoisomerase I by against Scl-70, hindrance of RNA association by hostile to snRNP) (14). ANA immunofluorescent testing is a quick and touchy screening strategy for ANA location and remains the best quality level for clinical testing. ELISA is additionally an extremely delicate and quick strategy for identifying autoantibodies (15).

Association of ANA with autoimmune diseases:

An immune system ailment happens when antigens from a living being are assaulted via autoantibodies because of hindered self-resistance on a base of various elements that incorporates provocative pathogens, adjusted receptors, radiation, or hereditary foundations (16). As a rule, this relationship is identified with cellintervened or humoral resistant responses to at least one of the body's self-structures (17). Immune system sicknesses, for example, lupus, 
rheumatic incendiary malady, fundamental sclerosis, idiopathic fiery myopathies, and antineutrophil cellular material protein-related general vasculitis, are frequently connected with the event of non-organ explicit autoantibodies (1). Foundational immune system sickness occurs with the nearness of a serum autoantibody titer that is high in intracellular proteins and nucleic acids. These autoantibodies are alluded to as antinuclear antibodies in light of their prevailing reactivity with atomic antigens, yet they likewise incorporate anticytoplasmic antibodies, tests for ANA have high symptomatic affectability and are viewed as the best test for screening for this issue (7).

Clinical utility of antinuclear antibodies:

ANAs are helpful in the determination of ANA-related fundamental rheumatic infection (18). ANA is a significant test in conclusion, avoidance and checking of illness (19).

\section{Summary:}

Immune system sicknesses represent a different cluster of infections described by cell and humoral reactions against self. ANA might be a term for an outsized and heterogeneous group of momentum counter acting agent which are been against various parts of the cell, either inside the cell core or its cytoplasm, and are usually present in immune system ailments. Numerous tests are utilized for assurance of ANA, for example, circuitous antinuclear counter acting agent immunofluorescence tests and the ELISA test which is the for the most part utilized test. Different tests incorporate Flow cytometry, Multiplex Immunoassay, Passive haemagglutination, immunodiffusion , counter-immunoelectrophoresis

strategies, immunoprecipitation, and immunoblot. ANA has a significant role in the analysis, avoidance, and checking of immune system sicknesses.

\section{$\underline{\text { References }}$}

1- Sack U, Conrad $\mathrm{K}$ and Csernok $\mathrm{E}$. (2009): Autoantibody detection using indirect immunofluorescence on HEp-2 cells. Ann N Y Acad Sci ;1173:166-73.

2- Hoffmann-Vold AM, Gunnarsson $R$ and Garen T. (2015): Performance of the 2013 American College of Rheumatology/European League Against Rheumatism Classification Criteria for Systemic Sclerosis(SSc) in large, well-defined cohorts of SSc and mixed conne- ctive tissue disease. J Rheumatol;42:60

3- Chan EK, Damoiseaux J, Carballo OG, Conrad K, de Melo Cruvinel W, Francescan- tonio PL, Fritzler MJ, Garcia-De La Torre I, Herold M, Mimori T, Satoh M, von Mü- hlen CA and Andrade LE. (2015): Frontiers in immunology, in press. Report of the First International Consensus on Standardized Nomenclature of Antinuclear Antibody HEp-2 cell patterns. 4- Chan EK, Damoiseaux J, de Melo Cruvinel W, Carballo OG, Conrad K, Francescan- tonio PL, Fritzler MJ, Garcia-De La Torre I, Herold M, Mimori T, Satoh M, von Mühlen CA and Andrade LE (2016).

5- Humbel RL, Conrad K, Chan EKL, Fritzler MJ, Humbel RL, Meroni PL, Steiner $G$ and Shoenfeld $Y$. (2013): Infection, Tumors and Autoimmunity. Lengerich: Pabst Science Publ p. 327-39.

6- Kavanaugh A, Tomar R, Reveille J, Solomon DH and Homburger HA. (2000): Guideli- nes for clinical use of the antinuclear antibody test and tests for specific autoantibodies to n- uclear antigens. American College of Pathologists. Arch Pathol Lab Med ;124:71-81.

7- U. Sack, K. Conrad and E. Csernok. (2009): Autoantibody detection U. Sack, K. Conrad, E. Csernok et al., Autoantibody detectionusing indirect 
immunofluorescence on HEp-2 cells, $\|$ Annalsof the New York Academy of Sciences, vol. 1173, pp. 166-173.

8- K. Conrad, D. Roggenbuck, D. Reinhold and U. Sack. (2011): Autoan- tibody diagnostics in clinical practice, Autoimmunity Reviews, vol. 11, no 3, pp. 207-211.

9- Bizzaro N, Tozzoli $R$ and Shoenfeld Y. (2007): Are we at a stage to predict autoimmune rheumatic diseases? Arthritis Rheum ; 56:1736-44.

10- Shoenfeld Y, Blank M, Abu-Shakra M, Amital H, Barzilai $O$ and Berkun Y. (2008): The mosaic of autoimmunity: prediction, autoantibodies, and therapy in autoimmune diseases. Isr Med Assoc $\mathrm{J} ; 10: 13-9$.

11-Arthur Kavanaugh MD ; Russell Tomar, MD; John Reveille, MD; Daniel H. Solomon, MD, MPH; Henry A. and Homburger, MD. (2000): (Arch Pathol Lab Med ;124:71-81). autoantibodies. J Clin Invest;95:2672-9.

12- Nielent MM, van Schaardenburg D and Reesink HW. (2004): Specific autoantibodies precede the symptoms of rheumatoid arthritis: a study of serial measurements in blood donors. Arthritis Rheum ;50:380-386.

13- Yamasaki Y, Honkanen-Scott $M$ and Hernandez L. (2006): Nucleolar staining cannot be used as a screening test for the scleroderma marker antiRNA polymerase I/III antibodies, Arthritis Rheum 54:3051-3056.

14- Meroni PL and Schur PH. (2010): ANA screening: an old test with new recommendations Ann Rheum Dis ;69:1420-2.

15- Salamunic I. (2010): Laboratory diagnosis of autoimmune diseases-new technologies, old dilemmas. Biochemia Medica ;20:45-56.

16- Lernmark A. (2001): Autoimmune diseases: are markers ready for prediction. J Clin Invest;108:109

17- Philippe Willems, Ellen De Langhe, Jolien Claessens, René Westhovens, Erna Van Hoeyveld, Koen Poesen, Steven Vanderschueren, Daniel Blockmans and Xavier Bossuyt. (2018).

18- Conrad K, Roggenbuck D and Reinhold D. (2012): Autoantibody diagnostics in clinical practice. Autoimmun Rev;11:207. 